\title{
The type locality of a giant salamander, Andrias japonicus (Temminck \& Schlegel, 1838)
}

\author{
KOJI IIZUKA
}

5-10-8 Sendagi, Bunkyo-ku, Tokyo 1130022, Japan

Author Email: salamander3227@gmail.com

G iant salamanders were discovered on the Tokaido trail in Japan approximately 190 years ago by European herpetologists. Andrias japonicus, originally named Triton japonicus: type locality, Suzuka-toge, Mie prefecture (Temminck, 1836) (Figs. 1, 2). The type locality was described only as coming from Okude in the area of Suzuka-toge, but with detailed locality information not recorded (Temminck, 1836; Hoogmoed, 1978, see Fig. 2). Andrias japonicus was first catalogued by Europeans when the resident physician of Dejima Island in Nagasaki, Philipp Franz von Siebold (February 17, 1796 - October 18, 1866), captured two individuals and shipped them back to Leiden in the Netherlands, in the 1820s. Coenraad Jacob Temminck (March 31, 1788 - January $30,1858)$ and his colleague described these salamanders as Salamandra maxima in Fauna Japonica (Temminck \& Schlegel, 1838). The giant salamander can be found on the islands of Kyushu, Honshu, and Shikoku in Japan and are listed as vulnerable (IUCN 2004) and as an endangered species as early as 1952 by the Agency for Cultural Affairs of the Japanese government. It is federally protected in Japan. To confirm habitat types, three known localities were visited, Honshu islands, i.e., Ikuno-cho, Hyogo prefecture in 1995, Wara-cho, Gifu prefecture in 2008 and Nabari-shi, Mie prefecture. The habitats were creeks in woodland areas and/ or mountain forests. An important difference between their former habitats and present-day habitat in the Suzuka-gawa creek, as described by Siebold collection in 1826, is that in the latter environment there are now no large flat stones normally used as retreat sites (Fig. 3).

Between 2010 and 2017 searches were made for suitable salamander habitat along the $495 \mathrm{~km}$ historic Tokaido trail from Tokyo to Kyoto in an attempt to locate potential sites that could present the type localities for two species of salamander: Onychodactylus japonicus (Houttuyn, 1782, lizuka et al., 2011) and A. japonicus. Between May and August 2017, searches were also made for suitable habitats in the Suzuka-toge region, Mie prefecture, which could also represent the potential type locality of $A$. japonicus (Figs. 1, 2). During surveys no $A$. japonicus were found in this locality and the available habitat within the areas searched did not appear suitable for $A$. japonicus (Fig. 3 ). It is therefore suggested that the true origins of $A$. japonicus were not from the Suzuka-toge region, Mie prefecture but possibly transported there from nearby areas by villagers.

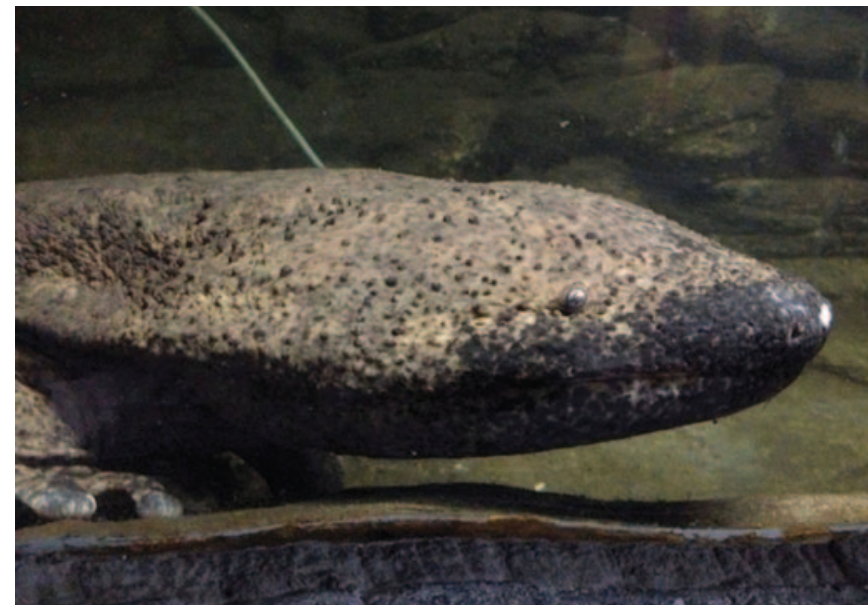

Figure 1. Andrias japonicus, photographed at the Museum of Salamanders, Akame, Nabari-shi, Mie prefecture on June 5, 2017

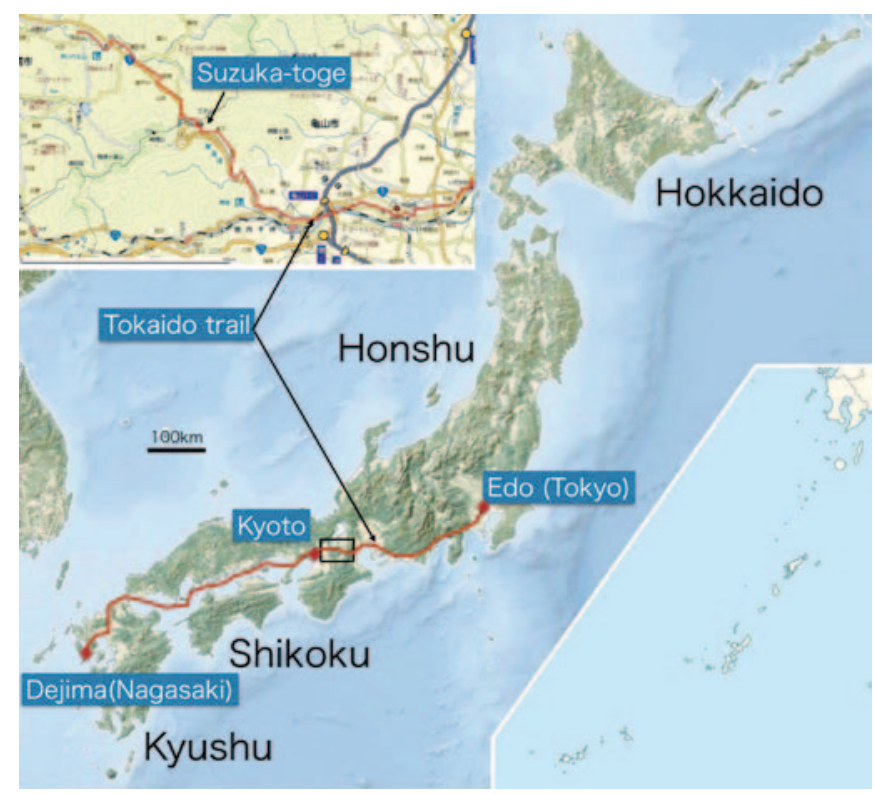

Figure 2. Maps showing the location of search routes in this study. Red lines on the maps are the author's study route of the Toakido trail, i.e., total approximately $495 \mathrm{~km}$ walking from Tokyo to Kyoto. Squares are indicated Suzuka-toge region. The old road and ship route within Seto-naikai Sea are coloured as a red line from Dejima in Nagasaki through Suzuka-toge to Edo (old Tokyo) that was travelled by Siebold in 1826 . 


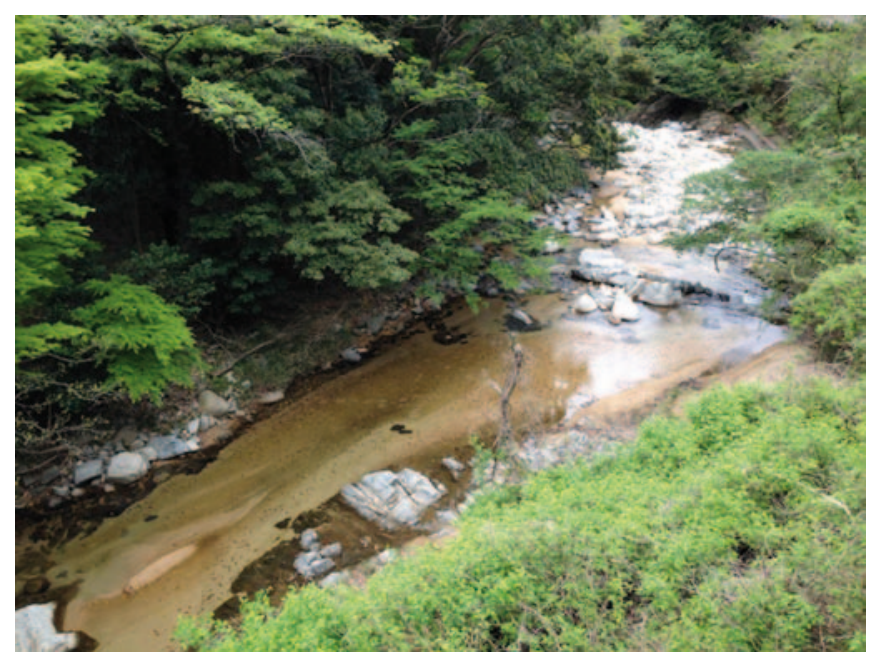

Figure 3. Riverbed environment in Suzuka-gawa river, that was searched for $A$. japonicus without success

A valuable future study would be a comparative analysis of DNA using the tissues of the type specimen deposited in Naturalis, Netherlands, and tissues of oral cavity epithelium including water samples around their habitats in several populations that seem to indicate the type locality, Mie prefecture. Molecular analysis may need to be undertaken if the type locality of $A$. japonicus is to be determined but this would be dependent on the ability to retrieve genetic material from the preserved type specimens for comparison with samples collected from the proposed region that surrounds the type locality. It is not possible to say how the type series is preserved, as this will dictate how difficult it may be to retrieve genetic material.

\section{ACKNOWLEDGEMENTS}

I would like to thank following colleagues; Kraig Adler, Tamotsu Kusano, Tomoko Takayama, Yoshinori Takeuchi and Edward Hullsiek. I also thank an anonymous referee for reviewing this work.

\section{REFERENCES}

Amphibian Species of the World (AMNH). Version 6.0. Andrias japonicus (Temminck, 1836). <http://research.amnh. org/vz/herpetology/amphibia/Amphibia>Downloaded on 29 January 2019.

IUCN (2004). The IUCN Red List of Threatened Species. Version 2004. <www.iucnredlist.org>. Downloaded on 29 January 2019.

Hoogmoed, M. S. (1978). An annotated review of the salamander types described in the Fauna Japonica. Zoologische mededelingen uitgegeven door het Rijksmuseum van Natuurlijke historie te Leiden (Ministerie van cultuur, recreatie en maatschappelijk weak) Deel 53 : 102. (in English)

Houttuyn, M. (1782). Het onderscheid der salamanderen van de haagdissen in't algemeen, en van de gekkos in't byzonder. Verhandel. Zeeuwsch. Genootsch. Wetensch. Lissingen 9: 306-336. (in Dutch)

lizuka, K., Poyarkov, N. A. and Koishi, H. (2011). Lectotype specimen of Japanese clawed salamander, Onychodactylus japonicus (Houttuyn 1782) collected by P. F. von Siebold. The Bulletin of Herpetological Society of Japan 2011: 122-127. (in Japanese with English abstract)

Temminck, C. J. and Schlegel, H. (1838). Fauna Japonica. Les Sauriens. Les Batraciens. Vol. 3. In Seibold, P. F. Von (Ed.) Fauna Japonica sive Descriptio Animalium, quae in itinere per Japoniam, jussu et auspiciis Superioum, qui summum in india Batava imperium tenant, suscepto antis 1823-1830, collegiate, notis, observationibus et adumbrationibus illustrativ, Lugduni Batavorrum, Amsterdam. 329 pp. (in French) 